\title{
PARQUE ESTADUAL DO IBITIPOCA, USO PÚBLICO E AS REPERCUSSÕES NO ARRAIAL DE CONCEIÇÃO DO IBITIPOCA, LIMA DUARTE/MG
}

\author{
Raquel Fernandes Rezende ${ }^{1}$ \\ Luiz Renato Vallejo ${ }^{2}$
}

\section{RESUMO}

O turismo nas unidades de conservação, particularmente nos parques naturais, gera interferência no ordenamento territorial interno e em suas vizinhanças. Além dos benefícios ambientais, econômicos e sociais, ocorrem alterações nos usos, acontecem conflitos e repercussões no planejamento territorial. Este artigo traz informações sobre a pesquisa realizada no Parque Estadual do Ibitipoca (PEIb) e seu entorno, porção localizada no Distrito (Arraial) de Conceição do Ibitipoca, município de Lima Duarte, Minas Gerais. O Parque apresenta elementos físicos naturais que se expressam em paisagens exuberantes e atrativas à visitação. No distrito existe um núcleo turístico que dá suporte aos visitantes e preserva atrativos históricos. O turismo aumentou consideravelmente desde o final da década de 1980 e ocasionou mudanças importantes na ocupação e uso do solo de Conceição do Ibitipoca. Visando o ordenamento adequado e ambientalmente sustentável das atividades no entorno do parque, foram estabelecidas políticas públicas regulatórias, nem sempre colocadas em prática pelos governos municipais e outros agentes. Isso contribuiu para que os interesses e demandas de outros atores, como empresários e promotores de eventos, prevalecessem sobre questões coletivas de maior relevância. Após 1995, o número de visitantes do PEIb aumentou consideravelmente, junto com os conflitos relacionados à especulação imobiliária, loteamentos clandestinos, insuficiência de infraestrutura sanitária (lixo, esgotos e água tratada), insegurança, êxodo rural, perdas de traços culturais locais, etc. A população nativa de Conceição do Ibitipoca mostra-se dividida, pois uma parcela é favorável ao desenvolvimento da atividade turística, enquanto outros opinam contrariamente.

Palavras chave: Conservação da natureza; turismo; ordenamento territorial

\section{IBITIPOCA STATE PARK, PUBLIC USE AND THE INFLUENCES IN THE LOCALITY OF CONCEIÇÃO DO IBITIPOCA, LIMA DUARTE/MG}

\section{ABSTRACT}

Tourism in protected areas, particularly in natural parks, generates interference in land use within and outside. In addition to the environmental, economic and social benefits, there are changes in the uses, conflicts occur and repercussions in the territorial planning. This article presents information about the research carried out in Ibitipoca State Park (PEIb) and its surroundings, a portion located in the District (Arraial) of Conceição do Ibitipoca, municipality of Lima Duarte, Minas Gerais, Brazil. The Park presents natural physical elements that express themselves in exuberant landscapes and attractive to visitation. In the district there is a tourist nucleus that gives support to the visitors and preserves historical

\footnotetext{
${ }^{1}$ Geógrafa, Doutora em Geografia pela Universidade Federal Fluminense.

E-mail: quelgeorezende@yahoo.com.br

${ }^{2}$ Prof. Titular. Programa de Pós Graduação em GeografiaUniversidade Federal Fluminense.

E-mail: luizrenato@id.uff.br
} 
attractions. Tourism has increased considerably since the late 1980s and has led to important changes in land use and occupation in Conceição do Ibitipoca. Aiming at the adequate and environmentally sustainable management of the activities surrounding the park, public regulatory policies were established, not always implemented by municipal governments and other agents. This contributed to the interests and demands of other actors, such as entrepreneurs and event promoters, prevail over collective issues of greater relevance. After 1995, PEIb visitors increased considerably, along with conflicts over land speculation, clandestine settlements, lack of sanitary infrastructure (garbage, sewage and treated water), insecurity, rural exodus, loss of local cultural traits, etc. The opinions of the native population of Conceição do Ibitipoca are not unanimous, having favorable and contrary positions regarding the growth of tourism.

Word Keys: Nature conservation; tourism; land use planning

\section{INTRODUÇÃO}

As políticas públicas de proteção da natureza através da criação de unidades de conservação (UC), como no caso dos parques naturais, criam benefícios ecológicos e ambientais, além das possibilidades de desenvolvimento socioeconômico para as regiões e áreas onde as unidades se situam. Destacamos o turismo como uma das atividades decorrentes, sobretudo para o desenvolvimento do "entorno dos parques, nos quais as populações passam a contribuir decisivamente na recepção, prestação de serviços ou no incremento da atratividade local" (SANTOS, et al, 2012, p. 46). Dessa forma, a atividade turística proporciona o surgimento de novas formas de produção e reprodução do capital.

O turismo caracteriza-se como um dos fenômenos mais dinâmicos e complexos da sociedade, com forte incidência na produção, transformação e organização do território. Sua relação com o território ocorre através da apropriação por uma prática social, com vistas à produção de territórios turísticos. Estes são construídos e desconstruídos socialmente, de forma permanente ou cíclica (SOUZA, 2006). Assim, muitas vezes, ocorre o processo de ordenamento ou reordenamento territorial seguindo a "ideia de uma orientação para um fim" (MOREIRA, 2011, p.77). Este processo desencadeia diferentes alterações no uso e ocupação do solo, aumento de pessoas que circulam e visitam determinadas áreas, surgimento de novas políticas capazes de darem conta desta demanda crescente, alterações econômicas, sociais e culturais das comunidades locais.

Entre as muitas ações que visam o ordenamento do território, cabe destacar o planejamento, especialmente quando realizado pelo Estado, podendo ocorrer através de Planos Diretores, Planos de Manejo, Planos Municipais, Legislações, entre outros, com a função de estabelecer diferentes análises e propostas às áreas em questão de forma menos predatória possível (VASQUES, 2008).

Neste contexto, o artigo explora as transformações na área urbana do Distrito de Conceição do Ibitipoca (Arraial de Ibitipoca), acesso direto ao Parque Estadual do Ibitipoca (PEIb). Criado em 4 de julho de 1973, tem área de 1.488 hectares e encontra-se numa disjunção do Complexo da Mantiqueira, domínio fitogeográfico da Floresta Atlântica com 
altitudes que variam entre 1.200 e $1.784 \mathrm{~m}$. Abriga uma valiosa amostra da vegetação primitiva regional bem representada e preservada, incluindo a ocorrência de espécies endêmicas da flora.

O PEIb dispõe de vários atrativos naturais, como mirantes, picos, grutas, praias, piscinas naturais e cachoeiras atraindo visitantes desde meados do século XX (FONTOURA, 2008). A partir do final da década de 1980 o número de turistas cresceu expressivamente no PEIb e no Arraial de Conceição do Ibitipoca. Com a elevação no número de visitantes, cresceram também os empreendimentos vinculados à prestação de serviços de apoio turístico (hospedagem, alimentação, transporte, lazer e etc.) e o Arraial de Conceição de Ibitipoca transformou-se, deixando em segundo plano as atividades agropecuárias tradicionais (FONTOURA, 2008). Desse modo, o Arraial passou à condição de um núcleo turístico de suporte à visitação do PEIb. As normas e os instrumentos de planejamento têm o papel de buscar o conhecimento sobre a realidade do Distrito e ordenar o turismo, evitando-se maiores impactos que não privilegiem o interesse coletivo.

Com base neste contexto, o artigo teve como principal objetivo descrever e avaliar as relações entre a presença do parque e seus usos, principalmente o turístico, na organização espacial do Arraial de Conceição do Ibitipoca, MG.

\section{PROCEDIMENTOS METODOLÓGICOS}

Trata-se de uma pesquisa qualitativa tendo como referência os trabalhos de Triviños (1987) e Costa (2011). Na pesquisa qualitativa busca-se no ambiente natural a fonte direta dos dados e o pesquisador atua como instrumento-chave. A pesquisa é descritiva, os fenômenos estão impregnados de significados que o ambiente lhes outorga. A investigação preocupa-se em atingir a profundidade dos significados, do visível e do não visível para atingir as relações e avançar no conhecimento (TRIVIÑOS, 1987).

Assim, na busca pela fidedignidade dos resultados, os pontos essenciais são: o conteúdo teórico no qual se apoia a pesquisa, e o contexto vivenciado pelos sujeitos, motivo pelo qual optamos pelo trabalho em campo junto aos atores que estão envolvidos com o processo de planejamento, ordenamento e ocupação da área de estudo.

Após a revisão bibliográfica pautada nos conceitos de Unidades de Conservação, Parques, Turismo, Uso Público e Ordenamento Territorial, foram feitas análises e integração entre eles, buscando-se a compreensão das relações que se estabelecem entre tais conceitos e as realidades espaciais na área de estudo.

Seguiu-se um levantamento documental-iconográfico, associado à análise, classificação, interpretação do material recolhido e estudo da cartografia disponível. Foram realizados diversos trabalhos de campo com objetivos diversos, entre os quais destacamos: i) reconhecimento de campo com documentação fotográfica (Arraial e PEIB); ii) identificação de usos do solo no Arraial; iii) entrevistas e reuniões com o gestor do parque e outros agentes administrativos; iv) entrevistas com representantes do governo municipal (turismo, cultura, 
meio ambiente, etc); e v) entrevistas com representantes de organizações sociais, universidades, entre outros.

A pesquisa também contou com a realização de mapeamentos feitos no Laboratório de Estudos da Paisagem, localizado no Departamento de Geociências da Universidade Federal de Juiz de Fora. Na produção dos mapas utilizou-se o Sistema de Informações Geográficas (SIG) com o intuito de gerar um produto auxiliar na identificação da área de estudo e das alterações do uso e ocupação do solo. Para tanto, foram adquiridas as bases municipais no site do Instituto Brasileiro de Geografia e Estatística em formato vetorial, as delimitações do PEIb e do Distrito de Conceição do Ibitipoca. Contou-se com o apoio da galeria de imagens orbitais disponibilizadas pelo software Google Earth neste processo de identificação e delimitação das áreas. Tais imagens orbitais foram trabalhadas no software Arc Gis 10.0 para a elaboração dos mapeamentos.

Para concretização do trabalho as informações foram cruzadas e interpretadas com vistas à compreensão da realidade de uma localidade que abriga uma UC com grande poder de atração de visitantes e turistas.

\section{O PEIB E A CONTEXTUALIZAÇÃO GEOGRÁFICA}

O Parque Estadual do Ibitipoca (PEIb) foi criado em 4 de julho de 1973 através da Lei Estadual $\mathrm{n}^{\circ}$ 6.126, ocupando uma área de 1.488 hectares. Preserva parcela do domínio fitogeográfico da Floresta Atlântica, Zona da Mata Mineira, no município de Lima Duarte/MG. Além do Distrito de Arraial de Conceição do Ibitipoca, o parque avança territorialmente nos municípios vizinhos de Santa Rita de Ibitipoca, ao norte, e Bias Fortes, a leste (Figura 01).

O clima da Serra do Ibitipoca é classificado como tropical de altitude mesotérmico, com inverno frio e seco, e temperaturas médias oscilando entre $12^{\circ} \mathrm{C}$ e $15^{\circ} \mathrm{C}$. No verão as chuvas são intensas e as médias térmicas oscilam entre $18^{\circ} \mathrm{C}$ e $22^{\circ} \mathrm{C}$ (ARAÚJO et al, 2007). A precipitação pluviométrica oscila entre 200 a $500 \mathrm{~mm} / \mathrm{mês}$ durante os períodos mais chuvosos, especialmente entre novembro e março. No período mais seco a média cai para 20 $\mathrm{mm}$ /mês (RODELA e TARIFA, 2002). Existem diferenciações topoclimáticos conforme a precipitação, temperaturas e umidade relativa do ar, a saber: i) arredores da serra, abaixo de aproximadamente 1.200 a $1.300 \mathrm{~m}$ de altitude; ii) áreas entre as escarpas de anticlinais, com altitudes aproximadamente entre 1.350 a $1.500 \mathrm{~m}$; iii) escarpas de anticlinais, sendo áreas mais elevadas da Serra, acima de aproximadamente 1.500 a $1.550 \mathrm{~m}$ de altitude e em alguns casos até mais de $1.700 \mathrm{~m}$ de altitude (RODELA e TARIFA, 2002).

Na região da Serra do Ibitipoca, também conhecida como Serra Grande (DELGADO, 1962) são registradas altitudes que variam entre 1.200 e 1.784 metros. A área está inserida nos limites dos domínios geomorfológicos da Serra da Mantiqueira e do Planalto de Andrelândia (ARAÚJO, 2007). Segundo o mesmo autor, esses domínios são formados predominantemente por colinas suaves, pouco resistentes à erosão. Em alguns locais, essas elevações suaves do terreno são intercaladas por cristas isoladas e alongadas, com vales profundos e serras 
escarpadas de grandes dimensões. Nas bases das encostas mais íngremes imensos colúvios arenosos são formados pelos solos transportados ao longo das encostas de morros (Figura 02).

Figura 01 - Lima Duarte/MG e Localização do Parque Estadual de Ibitipoca (PEIb)
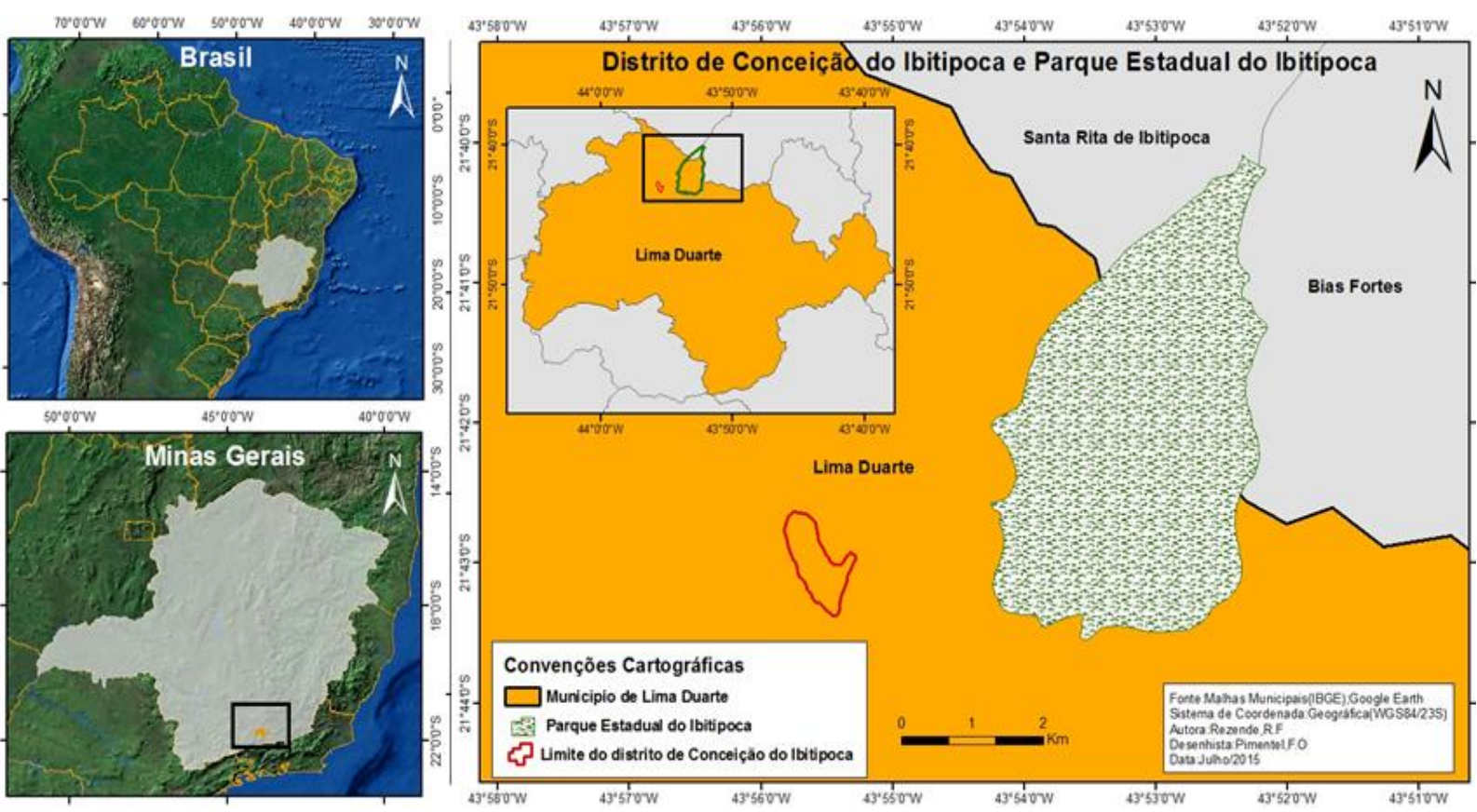

Figura 02 - Vistas panorâmicas no PEIb e entorno
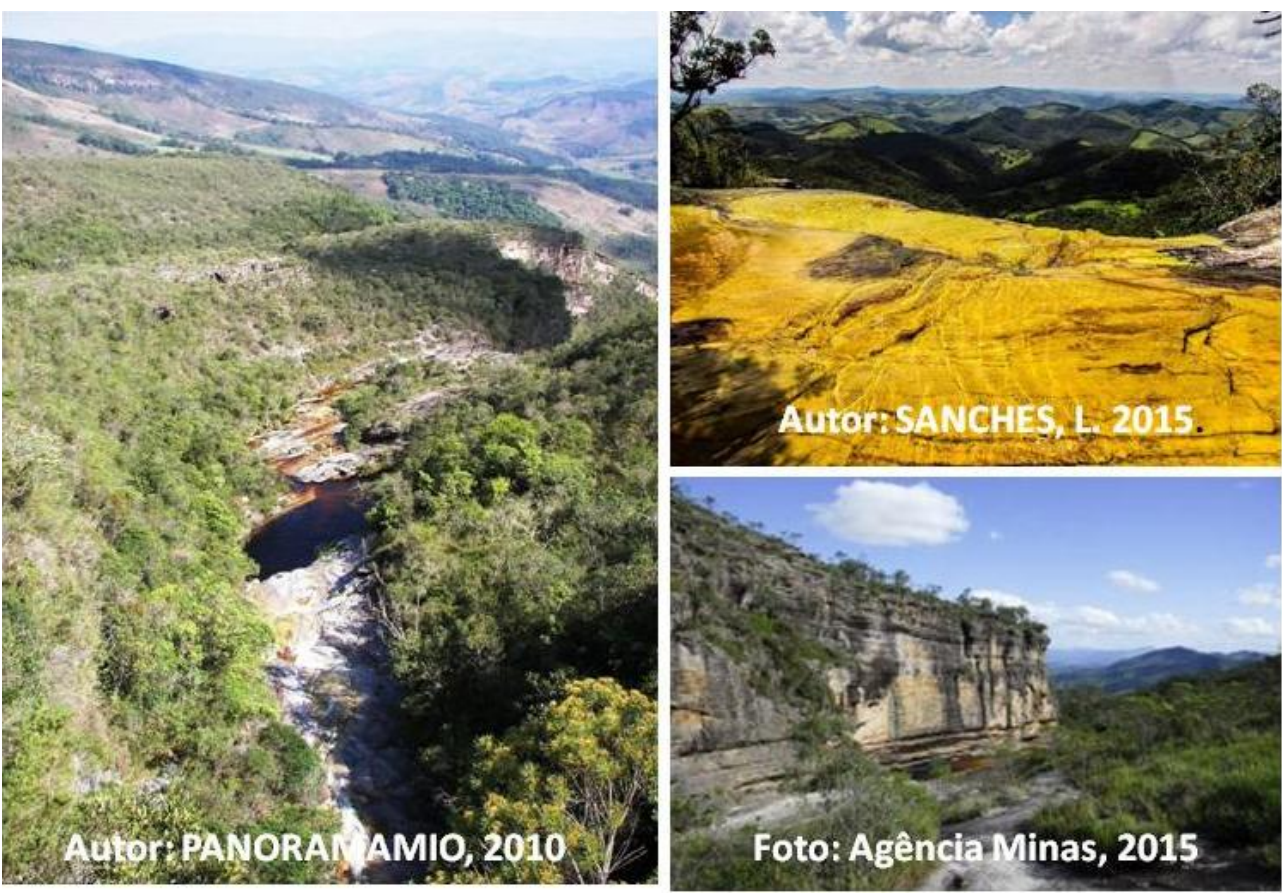
A Serra do Ibitipoca forma um dos conjuntos de relevos mais elevados da região de Lima Duarte. Os contrafortes são emoldurados por escarpas abruptas, sendo em parte formados com colúvios arenosos ou recobertos por cascalheiras grosseiras, com mais de $5 \mathrm{~m}$ de espessura. No Planalto dissecado no entorno da Serra, as formas de relevo são predominantemente colinosas, com morros de topos convexos até tabulares com vertentes convexas, intercaladas por cristas alongadas e assimétricas (ARAÚJO, 2007, p. 41).

A topografia atual da área do PEIb deve-se ao maior aprofundamento do intemperismo sob a intensa ação morfoclimática nas rochas gnáissicas presentes no local, tendo em vista sua menor resistência. Rodela (1988) considera que o controle estrutural e litológico (especialmente os dobramentos) predomina quando comparado com o intemperismo. $\mathrm{Na}$ paisagem do PEIB destacam-se cavernas, cânions de paredes verticais, dolinas de abatimento e pontes naturais, feições cársticas resultantes da lenta dissolução de rochas quartzíticas. De acordo com Rodela (1988) quinze cavernas presentes no Parque estão registradas pela Sociedade Brasileira de Espeleologia. Essas feições proporcionam importantes atrativos paisagísticos motivadores do uso público turístico e recreacional do parque e seu entorno.

Os solos verificados no PEIb são, em geral, rasos, arenosos, pobres em nutrientes e ricos em alumínio trocável, tendo em vista sua localização em cumieiras quartíziticas (ARAÚJO, 2007). Isso contribui na presença de uma vegetação de pequeno porte, com exceção das áreas de vales mais profundos e grotas, onde ocorre um maior acúmulo de materiais. Nas depressões do terreno os solos apresentam teores mais elevados de argila, onde a vegetação florestal de maior porte se apresenta.

O Rio do Peixe forma a principal drenagem da Serra do Ibitipoca junto com o Rio do Salto, seu afluente que nasce na Serra, "dividindo-a em duas faces ou flancos escarpados" (ARAÚJO, 2007, p. 40). O rio "percorre todo o vale central da serra no sentido sul numa distância aproximada de $5 \mathrm{~km}$, formando um verdadeiro cânion de encaixamento, entre as cotas altimétricas de 1.650 e 1.050 m, vertendo ao sul” (ARAÚJO, 2007, p. 40). Na Serra do Ibitipoca existe um número significativo de pequenos córregos e riachos, entretanto, somente os Rios do Salto e Vermelho apresentam parte de seus leitos dentro dos limites do PEIb e com volume razoável. O percurso do Rio Vermelho é feito no sentido norte, cuja distância aproximada é de $2 \mathrm{~km}$ dentro do Parque, com cotas altimétricas de 1.700 a $1.500 \mathrm{~m}$ de altitude, vertendo a noroeste.

Benites (2001) assinala que ao longo do período de chuvas, os complexos organometálicos formados por ácidos orgânicos e compostos ferruginosos são iluviados do solo e carregados pelas águas, contribuindo para a formação dos rios de águas pretas. São muitas as cachoeiras e lagos que se formam nos cursos d'água do PEIb, bem como em seu entorno. Estas apresentam grande beleza e qualidade e são importantes atrativos turísticos, especialmente ao longo do verão (Figura 03). 
O parque abriga uma valiosa amostra da vegetação primitiva regional com seus tipos fisionômicos principais: Candeial $^{3}$, Campo de Altitude, Campo Rupestre e Floresta Estacional Semidecidual, todos eles bem representados e preservados, especialmente, dentro dos limites territoriais do Parque. Em algumas porções do PEIb ocorrem espécies endêmicas da flora (ARAÚJO, 2007). A Serra do Ibitipoca situa-se no domínio fitogeográfico da Floresta Atlântica inserida na Cordilheira da Mantiqueira, paralelamente a Serra do Mar. Prevalecem as formações de campos de altitude (ARAÚJO et al, 2007, p. 53). Segundo o Vocabulário Básico de Recursos Naturais e Meio Ambiente do IBGE, os campos de altitude formam um tipo de vegetação campestre, descontínua e associada a afloramentos rochosos em ambientes montano e alto-montano com estrutura arbustiva e/ou herbácea que ocorre no cume das serras com altitudes elevadas, predominando os climas subtropical e temperado.

Figura 03 - Cachoeira dos Macacos (esquerda) e Lago das Miragens (direita)

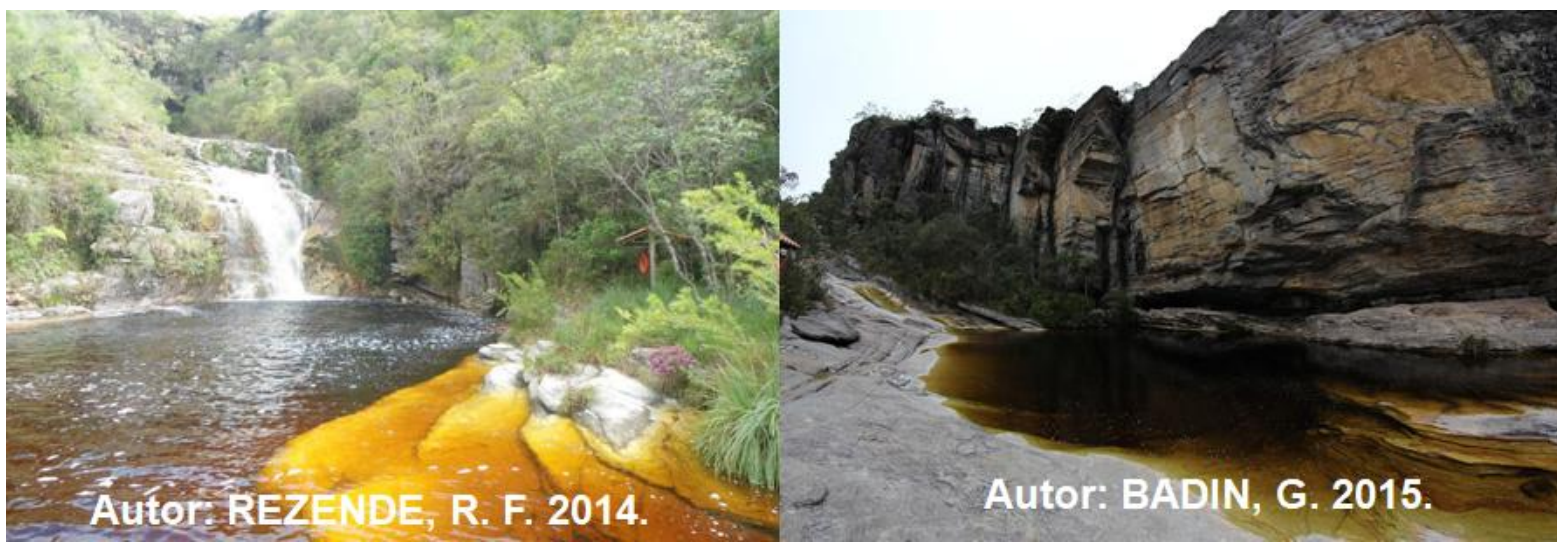

Essas comunidades florísticas são caracterizadas por grande número de endemismos (Brasil, 2004, p. 60). Dados do Plano de Manejo do PEIb (ARAÚJO et al, 2007) indicaram a seguinte situação da cobertura vegetal: Campos de Altitude (rupestre arbustivo e sensu stricto) ocupam a maior parte da área com 49,45\% (749,67 ha), seguido pelas Florestas Nebulares ou de Grota (290,87 ha - 19,19\%), Candeial (247,13 ha - 16,30\%), Floresta Ombrófila Densa (194,45 ha - 12.83\%), Campos Encharcados (17,39 ha - 1,15\%) e Cerrado de Altitude (12,84 ha - 0,85\%). As pastagens e áreas agrícolas ocupavam 0,24\% (194,45 ha).

As pressões humanas exercidas na área antes da criação do parque em 1973 deixaram marcas nas paisagens que atualmente se apresentam em vários estágios de regeneração, formando mosaicos com manchas florestais, campos de altitude (encharcáveis ou não) e

\footnotetext{
${ }^{3}$ Vegetação formada predominantemente pela Candeia, família Asteraceae, sendo considerada precurssora na invasão de campos. Cresce rapidamente em campos abertos e forma povoamentos mais ou menos puros. Existem várias espécies de candeia, porém a Eremanthus erythropappus (DC.) Macleish e a Eremanthus incanus (Less.) Less são as de maior importância econômica e de maior ocorrência em Minas Gerais. (SCOLFORO et al, 2002)
} 
cerrados. Nas áreas de transição entre as florestas ombrófilas e as formações campestres do Parque, ocorrem o candeiais (Figura 04).

Segundo o senso demográfico de 2010 do IBGE, o Arraial de Conceição do Ibitipoca abrigava 1.004 habitantes (534 são homens e 470 mulheres), sendo 494 pessoas na área urbana $(49,2 \%)$ e 510 em zonas rurais $(50,8 \%)$. O percentual de alfabetizados era de $75,7 \%$ (760 pessoas). Dos 331 domicílios particulares e permanentes recenseados, 188 estavam ligados à rede geral $(56,8 \%)$ e os demais dependiam de nascentes e poços. Sobre o esgotamento sanitário, 183 domicílios estavam ligados à rede geral de esgoto ou pluvial $(55,3 \%)$, enquanto o restante despejava em fossas (sépticas e rudimentares), rios e valas a céu aberto. Existia coleta regular de lixo residencial três vezes por semana e destinado a uma usina de triagem e compostagem.

Figura 04 - Diferentes feições da vegetação no PEIb

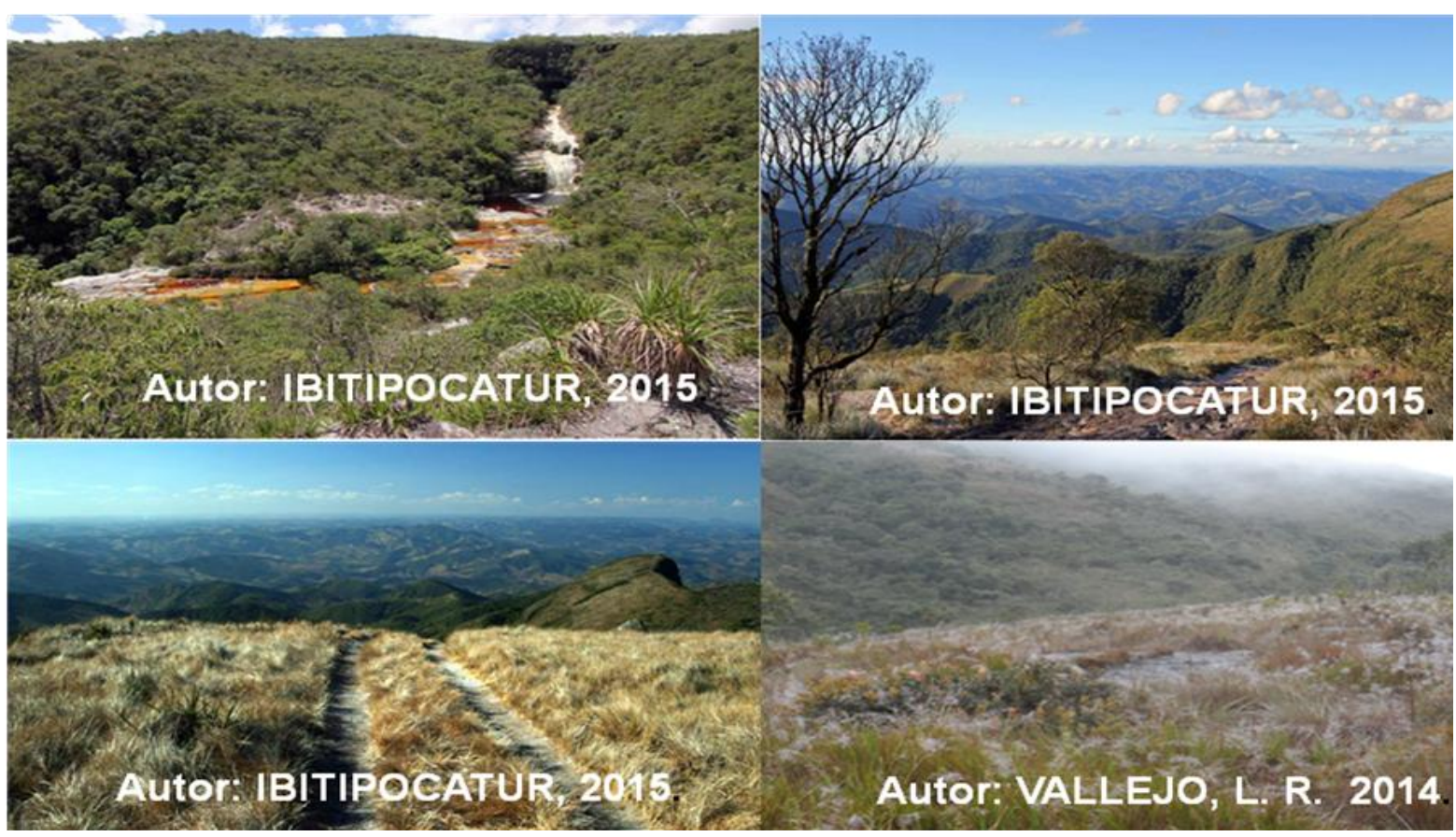

O turismo é a atividade econômica mais importante desde a década de 1980, havendo ainda a pecuária leiteira e agricultura de pequeno porte, atividades mais tradicionais desde o século XVIII. Saliente-se que a economia do local esteve alicerçada na exploração aurífera até o século XVIII. O Arraial já foi considerado um importante centro social da capitania de Minas Gerais, devido a sua localização entre a antiga capital Vila Rica e o Rio de Janeiro, ponto privilegiado e estratégico (BRANDT, 1994; DELGADO, 1962). Além, de ser local de arrecadação de impostos para a Capitania, pois parte de seus habitantes pagavam impostos pela posse da terra (especialmente, aquelas propriedades mais extensas), também havia a exploração aurífera e de escravos (RODRIGUES, 2001). 
As antigas reservas minerais se esgotaram gerando despovoamento e decadência do padrão econômico dos que permaneceram. Para as famílias que lá continuaram a viver, restou a prática da agricultura de subsistência, apoiada em técnicas primitivas e de baixa produtividade, como a produção agrícola voltada para o cultivo de gêneros alimentícios, como o milho, feijão, café e cana de açúcar (DELGADO, 1962).

Algumas marcas históricas ainda permanecem na localidade como a Matriz de Conceição do Ibitipoca (1768), importante atrativo turístico. Outras referências são citadas em trabalhos sobre as cavernas e grutas no interior do PEIb que teriam servido como abrigos para numerosos contingentes populacionais de negros e mulatos foragidos durante o período escravocrata (SAINT-HILAIRE, 1974; VALE, 1986; DELGADO, 1962; SILVEIRA, 1921).

\section{O USO PÚBLICO NO PEIB E AS IMPLICAÇÕES SOCIAIS E AMBIENTAIS}

Muito antes da criação do PEIb, a região já despertava interesses científicos de pesquisadores como Saint-Hilaire, que fez levantamentos sobre a vegetação em 1822 (DELGADO, 1962; DRUMOND, 1991; RODRIGUES, 2001). O viajante inglês Richard Burton (explorador, orientalista e cônsul da Inglaterra) percorreu a Serra do Ibitipoca em 1867 e o cientista Álvaro da Silveira, chefe da Comissão Geográfica e Geológica de Minas Gerais, também circulou pela região realizando mapeamentos em 1889 (DELGADO, 1962; BRANDT, 1994; RODRIGUES, 2001). Nestas incursões, além, das informações levantadas sobre os recursos naturais da Serra, os pesquisadores identificaram elementos do estilo de vida dos habitantes locais. Portanto, as áreas do atual parque e seu entorno já eram utilizadas por moradores tradicionais e visitantes, envolvendo atividades agrícolas, pecuária leiteira, expedições científicas e lazer.

Práticas religiosas também foram registradas na Serra Grande, nas áreas que hoje compõem o parque e vizinhanças. Por exemplo, o Pico do Pião $(1.762 \mathrm{~m})$, um dos atrativos do parque, ainda é muito procurado por turistas (Figura 05). Havia ali a Capela do Senhor Bom Jesus da Serra, onde as missas eram realizadas e assistidas pelos moradores que se dirigiam ao local em procissão (BRANDT, 1994).

Figura 05 - Pico do Pião e as ruínas da Capela do Senhor Bom Jesus da Serra

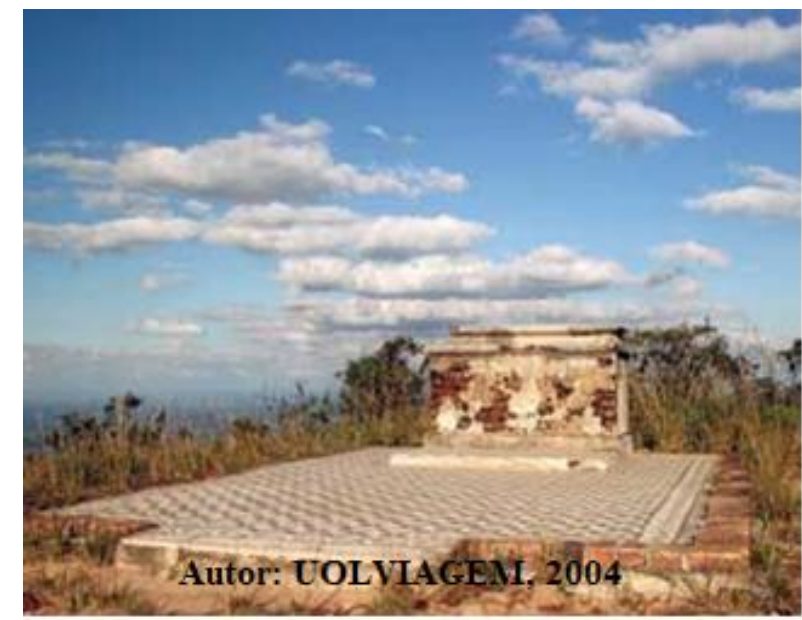


Em meados da década de 1920, eram realizadas missas, batismos e procissões na capela. Os fiéis dirigiam suas preces de chuva para conseguirem uma safra farta. No dia da festa de Bom Jesus da Serra, realizada em 4 de agosto, o Pico do Peão ficava "repleto de fiéis que chegavam de todos os lados, à cavalo ou em procissão, rezando e contemplando um verdadeiro "mar de morros" (RODRIGUES, 2001, p. 41). No ano de 1938 a antiga capela foi destruída por raios e ventos fortes, permanecendo apenas as ruínas da edificação. Atualmente é um dos pontos atrativos com vista privilegiada das cidades vizinhas e até da Serra de Teresópolis/RJ, em dias ensolarados e claros.

Outro atrativo religioso é o Morro do Cruzeiro (Figura 06) local adotado pela população para a devoção de sua fé (1.784 metros), transformado em um "altar natural", onde no dia de Santa Cruz a população se reunia para rezar o "terço cantado". Atualmente, os moradores, sobretudo os mais antigos, ainda mantém esse hábito diante da cruz de madeira no alto do morro. Este comportamento revela a relação dos moradores com a religiosidade e com os elementos naturais presentes na Serra. Os antigos pontos de referência usados pela população nativa deixaram de ter a mesma importância (RODRIGUES, 2001), mas ainda são atrativos turísticos de extrema beleza cênica.

As manifestações entre fé e natureza estiveram presentes no rio do Salto e a na Ponte de Pedra, onde "lichenes de várias cores, instalados nessas altas paredes verticais formam desenhos caprichosos" (DELGADO, 1962, p. 117). As pessoas viam imagens de santos realizadores de milagres, entre os quais, a figura de Santo Antônio (SAINT-HILARE, 1974), em uma das rochas pouco acima da Ponte de Pedra. O local já serviu como de ponto de devoção e oração, sendo um dos locais mais apreciados pelos turistas atualmente.

Schama (1996) associa esses hábitos culturais com as representações sociais da paisagem, evidenciando o caráter sagrado da natureza. Os elementos naturais como vales, rios, bosques e montanhas evocam uma interpretação "santificante" frente às suas características "espetaculares", "sobrenaturais" e "grandiosas". Essas manifestações agregam mitos, lembranças e obsessões (RODRIGUES, 2001, p. 42).

Figura 06 - Morro do Cruzeiro e ritual de soerguimento de uma nova cruz

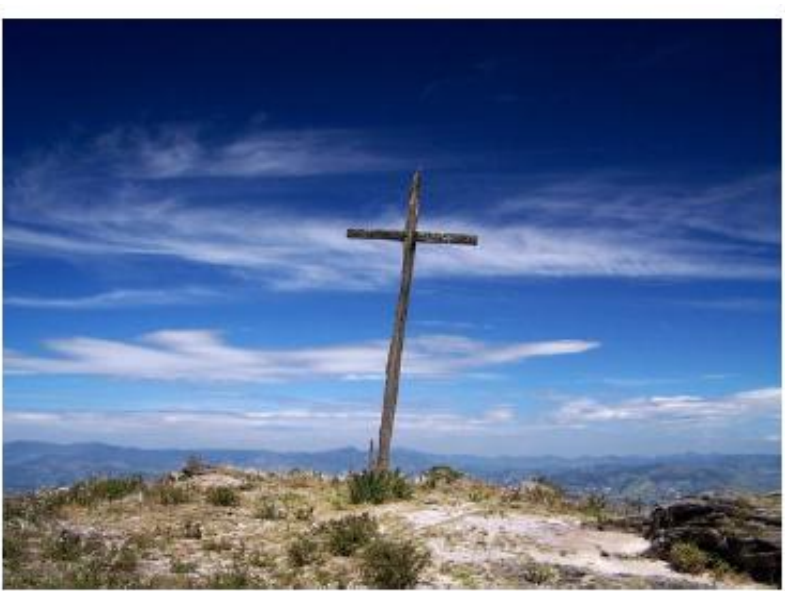

Autor: UOLVIAGEM, 2004

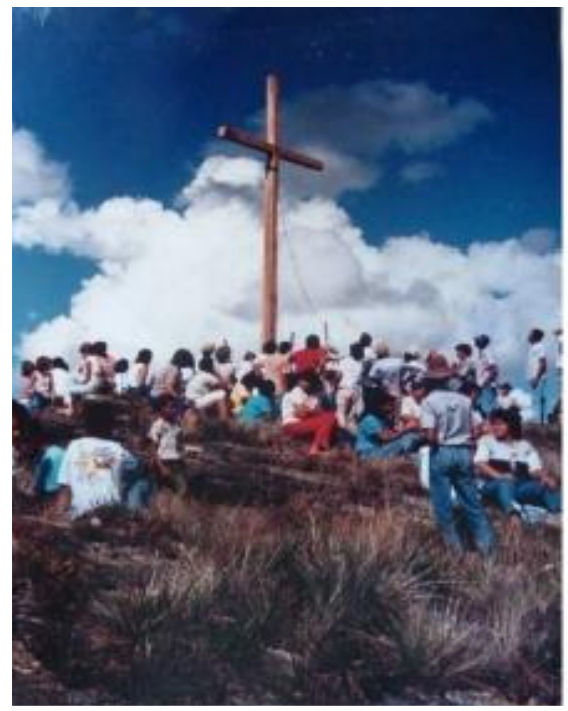

Autor: BEDIM apud PIRES, M. F. A. 
A ideia de se criar o PEIb, nos moldes do Parque Nacional Itatiaia, já vinha sendo manifestada desde a década de 1960 quando a região passava por um período de crise econômica e queda de seu quantitativo populacional. Muitos habitantes buscaram outras localidades para viver, tentando melhorar suas condições de vida (DELGADO, 1962). Após uma sequência de eventos, conflitos e esforços políticos, o governo de Minas Gerais criou o parque em 04/07/1973, através da Lei Estadual nº 6.126.

O turismo surgiu como um nicho econômico, especialmente após o ano de 1986, quando o parque passou a dispor da infraestrutura necessária para receber turistas. Desde então, foi verificado um aumento crescente de visitantes que passaram a frequentar a área imprimindo nova dinâmica de ocupação no parque e no Arraial, por conta da maior demanda de serviços vinculados aos turistas (RODRIGUES, 2001; CARVALHO, 2014). Um dos indicadores dessa nova realidade pode ser constatado no gráfico da Figura 07 que demonstra o crescimento da visitação no PEIb. A apreciação das paisagens, percursos nas trilhas, banhos de rio e nas piscinas naturais, visitação das cavernas, prática de camping, etc., são alguns dos motivos do crescimento significativo da visitação turística no parque. Dos cerca de 7.000 visitantes em 1988, chegou-se a quase 83.000 em 2015, ou seja, um número 12 vezes maior.

Figura 07 - Registros de visitantes no PEIb (1988 a 2015)

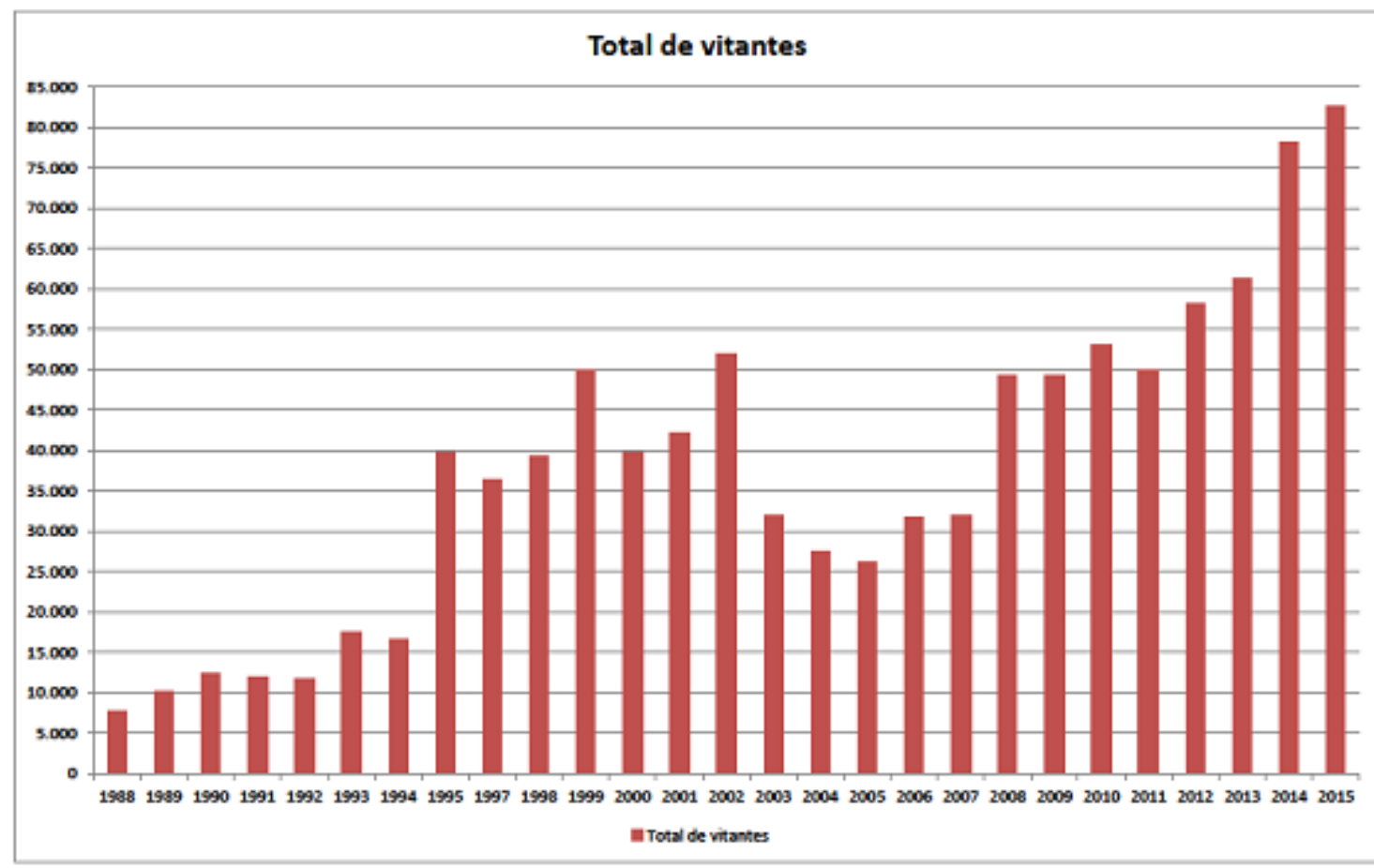

Fonte: IEF/MG, 2015

Paralelamente a esse incremento turístico, ocorreram mudanças significativas nas atividades regulares do local, na apropriação e no uso do solo de Conceição de Ibitipoca, destacando-se: 
$\checkmark$ estabelecimento de serviços de infraestrutura turística (hospedagem, alimentação, passeios e aventuras) com oferta de postos de trabalho e oportunidades;

$\checkmark$ intensificação na programação de eventos musicais e esportivos no Arraial;

$\checkmark$ ampliação de roteiros turísticos alternativos nas vizinhanças do território do PEIb;

$\checkmark$ aumento das áreas construídas (casas de segunda residência, ampliação das moradias da população local, pousadas, hotéis, lojas, restaurantes e bares) e ampliação do arruamento;

$\checkmark$ surgimento de novos loteamentos, sendo que em 2015 foram documentados 11 empreendimentos, sendo 5 regulares, 4 irregulares/clandestinos e $2 \mathrm{em}$ fase de regularização (dados obtidos no Departamento de Engenharia da Prefeitura Municipal de Lima Duarte, em julho de 2015).

As mudanças observadas trouxeram também repercussões sociais e ambientais negativas, assim destacadas:

$>$ limitações impostas pela criação do parque acabaram limitando o desenvolvimento das atividades econômicas tradicionais;

$>$ interferência nos costumes e modos de vida locais decorrentes da chegada de novas atividades econômicas ligadas ao turismo;

$>$ interesses políticos e econômicos de atores externos sobressaindo sobre a conservação de hábitos tradicionais e diretrizes ambientais de proteção da natureza;

$>$ aumento na produção de resíduos sólidos e dejetos por insuficiência de infraestrutura sanitária em períodos de maior fluxo turístico;

$>$ aumento do uso de drogas e violência em períodos de maior fluxo turístico, consequentemente maior insegurança;

$>$ problemas relacionados com a sobrevisitação do parque (excesso de carros e pessoas).

Neste novo cenário a convivência entre empreendedores, turistas, moradores locais e o poder público enfrenta fortes divergências. Uma parcela se vê prejudicada com a falta de planejamento e os prejuízos diretos e indiretos no modo de vida tradicional, enquanto outros estão mais envolvidos com a possibilidade de capitalizar dividendos resultantes da exploração turística. Os governos, em tese, mediadores dos conflitos, mostram-se muitas vezes ineficientes e tendenciosos a favor de propostas especulativas.

\section{CONCLUSÕES}

A implantação de uma unidade de conservação na categoria parque natural, é uma política pública que limita as atividades de exploração direta dos recursos naturais e traz benefícios diretos e indiretos à sociedade, mesmo que as populações não percebam isso imediatamente. Os parques naturais possibilitam usos indiretos como o lazer, o turismo, as pesquisas científicas, as práticas religiosas, além de outras ações consideradas como uso público. A mobilização das atividades dentro fora de seus limites alteram, brusca ou gradualmente, as realidades vigentes. $\mathrm{O}$ incremento da infraestrutura de apoio turístico junto com as atratividades naturais mobilizam interesses e investimentos, geram oportunidades e 
expectativas. Entretanto, não havendo diálogo e planejamento integrado com todos os atores envolvidos, além da necessária mediação nos conflitos que irão fatalmente emergir, todo o processo tende a acontecer de forma aleatória, favorecendo uns e prejudicando outros; produzindo impactos que afetam negativamente a maioria e não geram o lucro esperado pela minoria.

A criação do PEIb foi fortemente influenciada pela necessidade de alterar o estado de estagnação econômica em que a região se encontrava, sendo o turismo alçado como bandeira para alvancar a economia, sem desmerecer os valores paisagísticos, ecológicos e biogeográficos implicitos ao contexto geográfico do parque. Atualmente, o parque é um dos mais procurados e frequentados no estado de Minas Gerais, contando com boa infraestrutura de apoio para atender os visitantes. Entretanto vem sofrendo ultimamente o dilema da sobrevisitação que traz consequências negativas à conservação e requer iniciativas limitantes de acesso e do próprio uso público turístico.

O grande fluxo turístico trouxe mudanças no uso do solo de Conceição de Ibitiboca incrementando a supressão da vegetação e ocupação de áreas até então inabitadas, gerando adensamento e problemas de infraestrutura urbana. Atividades alternativas como shows e festivais procuram atrair mais visitantes, mas intensificam os problemas já existentes de um espaço urbano com condições e acessos restritos. Além disso, o crescimento urbano foi mais intenso que o planejamento e seus instrumentos regulatórios, denotando indefinição e incompetência no papel do poder público, principalmente o municipal. Portanto, a prática da mediação tem sido ineficitente, para não dizer ausente.

Muitas das normas estabelecidas não chegaram a ser colocadas em prática por diversos motivos. O poder público municipal foi ineficiente no cumprimento e fiscalização das normas destinadas à gestão do uso e ocupação do solo em Conceição do Ibitipoca. Isso contribuiu para que o território passasse a ser ordenado e reordenado conforme interesses e demandas de outros atores (empresários e promotores de eventos). Após 1995 o número de visitantes do PEIb aumentou consideravelmente, assim como os conflitos, entre os quais destacamos: especulação imobiliária; irregularidades em loteamentos clandestinos e o modelo de parcelamento do solo; insuficiência de insfraestrutura sanitária (lixo, esgotos e água tratada); insegurança; êxodo rural; perdas de traços culturais locais e elevação do custo de vida para a população que ainda vive no Arraial. A população nativa de Conceição do Ibitipoca mostra-se dividida, pois uma parcela é favorável ao desenvolvimento da atividade turística, enquanto outros opinam contrariamente.

\section{REFERÊNCIAS BIBLIOGRÁFICAS}

ARAÚJO, M. A. R. et al. Elaboração de Plano de Manejo para o Parque Estadual do Ibitipoca - MG. 2007 
BENITES, V. M. Caracterização de solos e de substâncias húmicas em áreas de vegetação rupestre de altitude. Tese (Doutorado em Solos e Nutrição de Plantas) Universidade Federal de Viçosa, Viçosa. 2001. $74 \mathrm{f}$

BRANDT, MEIO AMBIENTE. Parque Estadual do Ibitipoca - Levantamento dos aspectos históricos e culturais. Relatório parcial. Volume III. Belo Horizonte-MG: Instituto Estadual de Florestas - IEF. 1994. [n.p.]

BRASIL. Lei $\mathrm{n}^{\circ}$ 9.985, de 18 de julho de 2000. Regulamenta o art. 225, $\S 1^{0}$, incisos I, II, III e VII da Constituição Federal, institui o Sistema Nacional de Unidades de Conservação da Natureza e dá outras providências. Disponível em: http://www.planalto.gov.br/ccivil_03/Leis/L9985.htm. Acesso em 12 de setembro de 2007.

BRASIL. Vocabulário básico de recursos naturais e meio ambiente. Brasília-DF: Instituto Brasileiro de Geografia e Estatística-IBGE, 2004. 332 p.

CARVAlho, V. do C. Participação Social no Planejamento do Uso Público no Parque Estadual do Ibitipoca, Minas Gerais. Dissertação (Mestrado) - Programa de Pós-Graduação em Engenharia Florestal - Lavras: UFLA, 2014. 61 p

COSTA, R. G. da S. Valores, Atitudes E Simbolismos: Estudo Da Percepção Dos Frequentadores Do Parque Mariano Procópio, Juiz De Fora, MG. (Mestrado) - Programa de Pós-Graduação em Geografia da Universidade Federal de Uberlândia, Uberlândia, 2011. $195 \mathrm{f}$

DELGADO, A. M. Memória histórica sobre a cidade de Lima Duarte e seu município. Juiz de Fora: Edição do autor, 1962. 340 p.

DRUMmond, J. A. A História Ambiental: Temas, Fontes e Linhas de Pesquisa, Estudos Históricos nº 8, p.177-197, 1991.

FONTOURA, L. M. Análise comparativa da territorialidade do turismo nos Parques Estaduais de Ibitipoca - MG e Vila Velha - PR. 160 p. Dissertação (Mestrado) - Programa de Pós-Graduação em Geografia - Curitiba: UFPR, 2008.

INSTITUTO BRASILEIRO DE GEOGRAFIA E ESTATÍSTICA. Estados. Disponível em: http://www.ibge.gov.br/estadosat/. Acesso em: 07 jan. 2015.

MINAS GERAIS. Instituto Estadual de Florestas. Parque Estadual do Ibitipoca. Disponível em: < http://www.ief.mg.gov.br/component/content/192?task=view >. Acesso em: 04 maio 2013.

MOREIRA, R. O espaço e o contraespaço: as dimensões territoriais da sociedade civil e do Estado, do privado e do público na ordem espacial burguesa. In: OLIVEIRA, M. P. de; HAESBAERT, R. \& MOREIRA, R. (Org). Território, Territórios ensaios sobre o ordenamento territorial. Rio de Janeiro: Lamparina, 2011, p. 72 - 108.

REZENDE, R. F. O Entorno das Unidades de Conservação: Relações entre Atividade Turística e Uso do Solo no Arraial de Conceição do Ibitipoca, Lima Duarte/MG. Niterói, 
Tese (doutorado). Programa de Pós Graduação em Geografia, Universidade Federal Fluminense, Niterói, 2017. 128 f

RODELA, L. G. Vegetação e uso do solo - Parque Estadual do Ibitipoca-MG (mapa, escala 1:25.000). Belo Horizonte-MG: Governo do Estado de Minas Gerais/Secretaria do Meio Ambiente/Instituto Estadual de Florestas, 1998.

RODELA, L. G.; TARIFA, J. R. O clima na Serra do Ibitipoca - sudeste de Minas Gerais. Revista Espaço e Tempo, n. 11, São Paulo: GEOUSP, 2002.

RODRIGUES, C. G. de O. O TURISMO E A RECONSTRUÇÃO DO ESPAÇO RURAL: O CAUSO DO ARRAIAL DE CONCEIÇÃO DO IBITIPOCA (MG).. Dissertação (Mestrado) - Programa de Pós-Graduação em Ciências em Desenvolvimento, Agricultura e Sociedade. Seropédica: UFRRJ, 2001.173 f

SAINT-HILARE, A. de. Segunda Viagem do Rio de Janeiro a Minas Gerais e a São Paulo, 1822. Trad. rev. E prefácio de Vivaldi Moreira. Belo Horizonte: Itatiaia, São Paulo: Ed. Da Universidade de São Paulo, 1974. (Reconquista do Brasil).

SANTOS, A. S. P. dos.; ALMEIDA, F. A. B.; COELHO, E. A. de e PIRES, M. F. A. Conhecimentos e saberes no entorno do Parque Estadual do Ibitipoca, MG: a realidade da comunidade do Mogol e os desafios para uma nova política de gestão territorial. Revista Geografias, Volume 08, Número 2, Dezembro de 2012. Disponível em: < http://www.cantacantos.com.br/revista/index.php/geografias/article/view/188 >. Acesso em: 05 mar. 2014.

SCHAMA, S. - Paisagem e Memória. Ed Cia. das Letras. 1996

SCOLFORO, J. R. S. et al. Manejo sustentado das candeias Eremanthus erythropappus (DC.) e McLeisch Eremanthus incanus (Less.) Less. Lavras: Universidade Federal de Lavras, 2002. p.1-18, 2002.

SILVEIRA, A. A. da. Memórias Chorographicas. Belo Horizonte: Imprensa Official, 1921, v. 153 p.

SOUZA, M. J. L. O Território: sobre espaço e o poder, autonomia e desenvolvimento. In: CASTRO, I. E.; GOMES, P. C. DA C.; CORRÊA, R. L. Geografia Conceitos e Temas. Rio de Janeiro: Editora Bertrand Brasil, 2006.

TRIVIÑOS, A. N. S. Pesquisa qualitativa. In: Introdução à pesquisa em Ciências Sociais: a pesquisa qualitativa em educação. São Paulo: Atlas, 1987.

VALE, C. M. Parques e Reservas de Minas Gerais: Parque Estadual de Ibitipoca. Meio Ambiente - Informativo da Secretaria de Estado de Ciência e Tecnologia, n. 9, p. 4, 1986. 
VAlLeJO, L.R. - Uso Público em Áreas Protegidas: Atores, Impactos, Diretrizes de Planejamento e Gestão. Revista Eletrônica Uso Público em Unidades de Conservação. Vol 1, no 1, 2013, Niterói/RJ. Disponível em: < http://www.periodicos.uff.br/uso_publico >

VASQUES, P. H. R. A Aplicação do Plano de Manejo, Zona de Amortecimento e Corredores Ecológicos na proteção da Biodiversidade. Relatório do NIMA - Núcleo Interdisciplinar do Meio Ambiente, Rio de Janeiro: 2008. Disponível em: <http://www.nima.puc-rio.br/index.php>. Acesso em: 06 set. 2013. 